\title{
CARACTERIZAÇÃO E FLOTAÇÃO DE MINÉRIO DE FOSFATO DO CHILE
}

\author{
M. P. PAIVA, A. POMPEO, R. T. RODRIGUES, J. RUBIO
}

Departamento de Engenharia de Minas, Universidade Federal do Rio Grande do Sul. Av. Bento Gonçalves, 9500, Porto Alegre, RS, 91501-970. e-mail: jrubio@ufrgs.br

Artigo submetido em novembro/2011 e aceito em dezembro/2011

\section{RESUMO}

Este trabalho resume estudos de caracterização e desenvolvimento de rota técnica de tratamento de um minério de fosfato do Chile. Os principais objetivos foram a adequação de tamanho de partícula e flotação para a obtenção de um concentrado com teores $>36 \%$ de P2O5 e com impurezas que permitam a produção de um fertilizante fosfatado. A caracterização tecnológica incluiu análises mineralógicas e de distribuição de espécies (elementos) por tamanho (granuloquímica), em particular de impurezas de arsênio. As amostras (duas) correspondiam a um minério pobre $(20-24 \%$ P2O5) e um "enriquecido" (27-29\% P2O5) com teores entre $40-47 \% \mathrm{CaO}, 89-100 \mathrm{ppm} \mathrm{As,} \mathrm{4-7 \%} \mathrm{SiO2,} \mathrm{2-4 \%}$ Fe2O3, 1-1,5\% MgO e 2-5\% Al2O3. As principais espécies minerais identificadas por DRX foram hidroxiapatita, actinolita, hornblenda, tremolita, clorita-serpentina, quartzo. Os melhores resultados de flotação, obtidos em estudos otimizados em bancada e de coluna $(200 \mathrm{~mL} / \mathrm{min})$ foram obtidos com a amostra "enriquecida" e classificada entre 37-149 $\mu \mathrm{m}$, oleato de sódio como coletor $(444 \mathrm{~g} / \mathrm{t})$ e óleo diesel $(100 \mathrm{~g} / \mathrm{t})$ como co-coletor "extender". Os teores (médios) dos concentrados foram 39\% de P2O5, $128 \mathrm{ppm}$ de As e baixas concentrações de impurezas (2,0\% SiO2, 0,5\% Fe2O3, 0,2\% MgO e 0,4\% Al2O3), recuperações de $\mathrm{P} 2 \mathrm{O} 5$ (>96\%), alcançando taxas de BPL de até $87 \%$ e razão $\mathrm{CaO} / \mathrm{P} 2 \mathrm{O} 5$ de 1,3 . A qualidade desses concentrados é condizente para fabricação de um insumo fertilizante. Não foram identificadas espécies de arsênio via DRX ou MEV devido a seu baixo teor. Entretanto, foi encontrada via análise de FRX, técnica desenvolvida para este minério, dos produtos de flotação uma correlação direta entre $\mathrm{Ca}$, $P$ e As, e inversa entre Fe e As. Conclui-se que o As está associado aos minerais de apatita, sendo o $\mathrm{P}$ substituído pelo As em sua estrutura, dificultando a remoção por métodos físicos. Estes resultados foram discutidos em termos dos parâmetros químicos, físicos, mineralógicos e interfaciais envolvidos

PALAVRAS-CHAVE: fosfato; rota técnica; caracterização; flotação.

\section{CHARACTERIZATION AND FLOTATION OF PHOSPHATE MINERAL FROM CHILE}

\begin{abstract}
This work summarizes studies of development of a technical route for processing of a Chilean phosphate mineral. Main aims were to adequate particle size and flotation parameters to obtain a high grade concentrate greater than $36 \%$ of P2O5 and impurities that enable the production of phosphate fertilizer. The technological characterization included mineralogical analysis and distribution of species (elements) by size, in particular arsenic impurities.
\end{abstract}

Samples (two) correspond to a low grade ore (20 to $24 \% \mathrm{P} 205$ ) and a high grade (enriched of phosphate) ore ( 27 to $29 \%$ of $\mathrm{P} 2 \mathrm{O} 5$ ). Other elements found in the sample were: $\mathrm{CaO}(40-47 \%)$, As (89-100 ppm), SiO2 (4.7\%), Fe2O3 (2-4\%), MgO (1-1.5\%) and Al2O3 (2$5 \%)$. Main mineral species determined by XRD were hydroxiapatite, actinolite, hornblend, tremolite, chlorite-serpentina, quartz. The best results of flotation tests, using optimized values of bench tests 
and column flotation tests $(200 \mathrm{~mL} / \mathrm{min})$, were reached using low grade sample and particle size between 37-149 $\mu \mathrm{m}$, sodium oleate as collector (444 $\mathrm{g} / \mathrm{t})$ and diesel oil $(100 \mathrm{~g} / \mathrm{t})$ as co- collector "extender". The average grades of concentrates were $39 \%$ of $\mathrm{P} 2 \mathrm{O} 5,128 \mathrm{ppm}$ of As and low grades of impurities (2\% SiO2, 0.5\% Fe2O3, 0.2\% MgO and 0.4\% Al203), recovery of P2O5 (>96\%), reaching BPL up to $87 \%$ and $\mathrm{CaO} / \mathrm{P} 2 \mathrm{O} 5$ ratio of 1.3 . The quality of these concentrates allows the fabrication of fertilizer.
Arsenic species were not found by XRD or SEM due to its low grade. However, it was found by XRF analisis, technique adapted to this work, a linear (direct) correlation among $\mathrm{Ca}, \mathrm{P}$ and $\mathrm{As}$ and inverse ratio between $\mathrm{Fe}$ and $\mathrm{As}$. It is concluded that As mineral is associated with apatite, and $\mathrm{P}$ replaced $\mathrm{As}$ into chemical structure, making it difficult to remove by physical methods. All results were discussed in terms of chemical, physical, mineralogical and interfacial parameters.

KEY-WORDS: phosphate; technical route, characterization, flotation.

\section{CARACTERIZAÇÃO E FLOTAÇÃO DE MINÉRIO DE FOSFATO DO CHILE}

\section{INTRODUÇÃO}

Os minérios de fosfato são rochas naturais que se formam em ambientes geológicos variados, sendo os mais comuns os fosfatos de cálcio do grupo da apatita. Quando em quantidade e concentração suficientes, formam depósitos de valor econômico. Estes minérios podem ser utilizados diretamente, ou após beneficiamento, na manufatura de produtos comerciais. Sua principal aplicação é na agricultura, como fertilizante (Loureiro et al., 2008).

A capacidade de ânions substituírem o fosfato da apatita não se restringe a $\mathrm{F}^{-}, \mathrm{CO}_{3}{ }^{-2}$ e $\mathrm{OH}^{-}$, que são encontrados nas diferentes variantes de apatita. Silicato, vanadato, aluminato, titanato e arsenato podem também ocorrer no lugar de parte do fosfato. Da mesma forma o cálcio pode ser substituído em parte por urânio, lantanídeos terras raras ou certos traços de outros metais como cádmio, zinco, bário, magnésio e estrôncio. Em alguns casos ocorre cloro no lugar de parte do flúor (Abouzeid, 2008).

A rocha fosfática requer processamento para reduzir o conteúdo de minerais acessórios (impurezas) incluindo o quartzo, chert, argila, feldspato, mica, calcita e dolomita. Na indústria de fertilizantes é necessário que os minérios de fosfato tenham teor de mais de $30 \%$ de $\mathrm{P}_{2} \mathrm{O}_{5}$, razão $\mathrm{CaO} / \mathrm{P}_{2} \mathrm{O}_{5}$ menor do que 1,6, e teor de $\mathrm{MgO}$ inferior a $1 \%$. Caso os minérios de fosfato não preencham estes critérios, é necessário remover suas impurezas por alguns meios de beneficiamento. Métodos aplicados na indústria como a calcinação, lixiviação ácida e separação magnética têm certas limitações e desvantagens quando comparados com a flotação (Sis e Chander, 2003).

Minerais semi-solúveis como a apatita, fluorita, calcita, scheelita, magnesita e barita são hidrofílicos, e a hidrofobização seletiva desses minerais com o uso de reagentes é determinante na eficiência do processo de separação. A separação dos minerais semi-solúveis dos minerais de silicato e óxidos tem sido eficiente pelo processo de flotação. No entanto, a separação entre estes minerais, como no caso da apatita e da calcita, apresenta dificuldades devido à similaridade das propriedades químicas superficiais dos minerais. Diferentes tipos e estruturas de reagentes são usados na flotação de minérios de fosfato como coletores, depressores e reagentes auxiliares na flotação direta e reversa destes minérios (Sis e Chander, 2003).

O processo Crago "Double float", utilizado na Florida, consiste na flotação da apatita com ácido graxo e óleo combustível em pH 9. O concentrado desta etapa passa por uma escrubagem ácida com 
ácido sulfúrico para remover os reagentes da superfície do fosfato. Após a lavagem, a sílica é flotada com amina em pH neutro. Já, no processo Crago reverso, a sílica é flotada primeiramente, com um coletor do tipo amina, sendo o concentrado desta etapa posteriormente submetido à flotação de apatita com ácido graxo e óleo combustível como coletor (Zhang et al., 1997).

Um processo de flotação reversa de impurezas de carbonato de metais alcalinos terrosos, particularmente dolomita e calcita, foi patenteado sob o título "Flotation of phosphate ores containing dolomite". Esse processo utiliza um sal de sódio de ácido oleico sulfonatado como coletor e o tripolifosfato de sódio como depressor do fosfato, com pH 5,5-6, regulado com ácido sulfúrico (Snow, 1982).

No caso da apatita proveniente de rochas ígneas, como é a grande maioria dos minérios fosfáticos Brasileiros, o processo de concentração da apatita é realizado com ácido graxo como coletor de apatita e da utilização de amido de milho como depressor dos minerais de ganga (Barros, 2006).

Os objetivos específicos deste trabalho foram a adequação de tamanho de partícula e flotação para a obtenção de um concentrado com teores $>36 \%$ de $\mathrm{P}_{2} \mathrm{O}_{5}$ e com impurezas que permitam a produção de um fertilizante fosfatado. A caracterização tecnológica incluiu análises mineralógicas e de distribuição de espécies (elementos) por tamanho (granuloquímica), em particular de impurezas de arsênio via análise por FRX, calibrado e otimizado.

\section{EXPERIMENTAL}

\section{Materiais e Métodos}

Minérios: Minério Pobre (11\%P) e Minério Enriquecido (13\%P). Foram utilizadas amostras de minério de fosfato provenientes da empresa Minera Formas, do Chile, identificadas como $11 \% \mathrm{P}$ (Pobre) e 13\%P (Enriquecido) para caracterização e ensaios de flotação, respectivamente. As amostras foram coletadas após processo de cominuição e classificação. A tabela I mostra os teores dos principais elementos constituintes. A amostra 13\% P foi classificada na fração 37-149 $\mu \mathrm{m}$ para os testes de flotação.

Tabela I. Teores dos principais elementos constituintes das amostras (11\%P e 13\%P).

\begin{tabular}{|c|c|c|c|c|c|c|c|}
\hline Amostr & $\mathrm{P}_{2} \mathrm{O}_{5}$ & $\begin{array}{ll} & \mathrm{CaO}, \\
\% & \end{array}$ & $\begin{array}{l}\mathrm{Fe}_{2} \mathrm{O}_{3}, \\
\%\end{array}$ & $\begin{array}{l}\text { As, } \\
\mathrm{ppm}\end{array}$ & $\begin{array}{ll} & \mathrm{MgO}, \\
\% & \end{array}$ & $\% \mathrm{SiO}_{2}$, & $\% \mathrm{Al}_{2} \mathrm{O}_{3}$, \\
\hline $11 \% \mathrm{P}$ & 20,5 & 32,2 & 4,5 & 113 & 1,8 & - & - \\
\hline 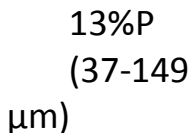 & 31,5 & 47,7 & 2,1 & 89 & 0,9 & 4,2 & 2,3 \\
\hline
\end{tabular}

Estudos de caracterização: Análise granuloquímica (Arsênio). Após a execução da análise granulométrica, foram separadas alíquotas de cada fração e enviadas à análise química de arsênio, realizada por ICP (Standard Methods 3120 B-ICP).

Análise de difração de raios- $X$. A técnica de difração de raios- $X$ foi realizada em um difratômetro Philips X'Pert, modelo MPD, usando tubo de cobre seguindo o procedimento experimental para análise total. Os minerais identificados nesta análise foram comparados a padrões de um banco de dados do software PANalytical Highscore Plus indicando as principais fases minerais da amostra. 
Análise de microscopia eletrônica de varredura (MEV). As análises de MEV foram realizadas em Microscópio JEOL, modelo JSM 5800, no Centro de Microscopia Eletrônica (CME-UFRGS).

Análise de fluorescência de raios- $X(F R X)$. As análises foram realizadas em um espectrômetro da PANanalytical, modelo MiniPal 4, Versão 7.0, com a aplicação Omniam de análise semiquantitativa. Para tanto, foram determinadas curvas de calibração a partir de padrões de elementos analisados por outras técnicas. O software Omniam foi utilizado em análises semiquantitativas para obtenção das melhores condições analíticas.

Reagentes: Foi utilizado oleato de sódio como coletor dos minerais portadores de cálcio. O coletor foi obtido após saponificação de ácido oléico com hidróxido de sódio, ambos P.A. (relação Óleo/ $\mathrm{NaOH}$ - 1:1) e secagem do produto em estufa a temperatura de 105-110 으 por 2 horas. Como agente extensor foi utilizado óleo diesel emulsificado comercializado nos postos de combustíveis de Porto Alegre-RS. Na emulsificação do óleo em água foi utilizado um agitador de alta rotação, marca Marconi, modelo MA 102 ("Turrax"), na concentração de 1\% p/v, com rotação de 20000 rpm, durante 10 min. Para ajuste de $\mathrm{pH}$, foram utilizadas soluções de hidróxido de sódio $(10 \% \mathrm{p} / \mathrm{v})$ e ácido sulfúrico $(10 \%$ $\mathrm{v} / \mathrm{v}$ ). Foi empregada água destilada/deionizada no preparo de todos os reagentes, e água de abastecimento público do município de Porto Alegre para ajuste da porcentagem de sólidos da polpa nos estudos de flotação.

Estudos de Flotação: Ensaios em célula mecânica. Os ensaios foram realizados em uma máquina Edemet de laboratório, utilizando uma célula quadrada em acrílico de 1,2 litros. A polpa com $40 \%$ de sólidos $\mathrm{p} / \mathrm{p}$ teve $\mathrm{pH} 6$ ajustado com hidróxido de sódio e ácido sulfúrico, usando um medidor de $\mathrm{pH}$ marca AnalionTM, modelo PM 608. O condicionamento foi realizado com oleato de sódio e óleo diesel (adicionados nesta ordem) durante $10 \mathrm{~min}$ em tanque agitado $(350 \mathrm{rpm})$. Após condicionamento, a polpa foi transferida à célula de flotação e diluída a $25 \% \mathrm{p} / \mathrm{p}$ operando com $5,5 \mathrm{~L} / \mathrm{min}$ de ar, controlado por um rotâmetro. A agitação foi mantida em $750 \mathrm{rpm}$ e o tempo de flotação foi de $2 \mathrm{~min}$. Foram avaliados os efeitos da dosagem de coletor (oleato de sódio: 200, 300 e 444 g.t $^{-1}$ ) e do agente extensor (óleo diesel: 100 g.t ${ }^{-1}$ ) nas recuperações e teores de $\mathrm{P}_{2} \mathrm{O}_{5}$ e das impurezas.

Ensaios em coluna. Os estudos de flotação com minério de fosfato foram realizados de forma comparativa entre a CCR-coluna convencional reta e a C3P-coluna de três produtos. Essa coluna modificada (figura 1) tem sido estudada durante anos no nosso grupo de pesquisa, a saber: flotação de sulfetos de cobre em escala piloto e de laboratório (Santander et al., 1994; Rubio, 1996), finos de fluorita (Rubio e López, 1992), sulfetos de chumbo e zinco (Cabral, 1996), partículas de ouro (Valderrama e Rubio, 2008) e minérios de fosfato (Matiolo et al.,2009). Os testes foram realizados em uma coluna convencional reta de laboratório (vidro) com diâmetro interno de 2,54 cm, 2,20 m de altura total e volume efetivo de 1,5 L, composta por cinco módulos de vidro ajustáveis, e da mesma forma com a C3P, com as mesmas dimensões e volume. A polpa ( $40 \%$ de sólidos $\mathrm{p} / \mathrm{p}$ ) foi condicionada em um tanque cilíndrico com volume de $10 \mathrm{~L}$ por $10 \mathrm{~min}$ com oleato de sódio $\left(444\right.$ g. $\left.\mathrm{t}^{-1}\right)$ a pH 6, com agitação a $350 \mathrm{rpm}$. Após o condicionamento, a polpa foi diluída a $25 \%$ sob agitação de $600 \mathrm{rpm}$. Desse tanque a polpa foi alimentada à coluna com o auxílio de uma bomba peristáltica marca Masterflex ${ }^{\circledR}$, modelo 7523-27. A altura da espuma foi fixada em $30 \mathrm{~cm}$ e mantida através da variação do fluxo da corrente do rejeito controlado por uma bomba marca Masterflex ${ }^{\circledR}$, modelo 7553-71. A velocidade superficial do fluxo de alimentação (Jalim) foi fixa em $0,66 \mathrm{~cm} \cdot \mathrm{s}^{-1}$, a do $\operatorname{ar}(\mathrm{Jg})$ em $0,49 \mathrm{~cm} \cdot \mathrm{s}^{-1}$ e a água de lavagem I (JW) em $0,25 \mathrm{~cm} \cdot \mathrm{s}^{-1}$. A flotação teve duração de $35 \mathrm{~min}$; sendo $15 \mathrm{~min}$ de estabilização, e 20 min de coleta. Os estudos de flotação na C3P seguiram o procedimento adotado nos estudos em CCR (níveis das variáveis operacionais), além da coleta do produto drenado da fase espuma. A 
adaptação da CCR para a C3P foi feita através da substituição do último trecho da CCR $(1,50 \mathrm{~m})$, para o trecho contendo a zona de inflexão.

As amostras foram pesadas em balança semi-analítica marca Sartorius, filtradas em um filtro a vácuo de laboratório (Denver), secas em estufa por $24 \mathrm{~h}$ a $100^{\circ} \mathrm{C}$, desagregadas, homogeneizadas e quarteadas para obtenção de alíquotas para análise química.

As mesmas foram feitas por espectroscopia de fluorescência de raios-X em um equipamento da PANanalytical, modelo MiniPal 4.

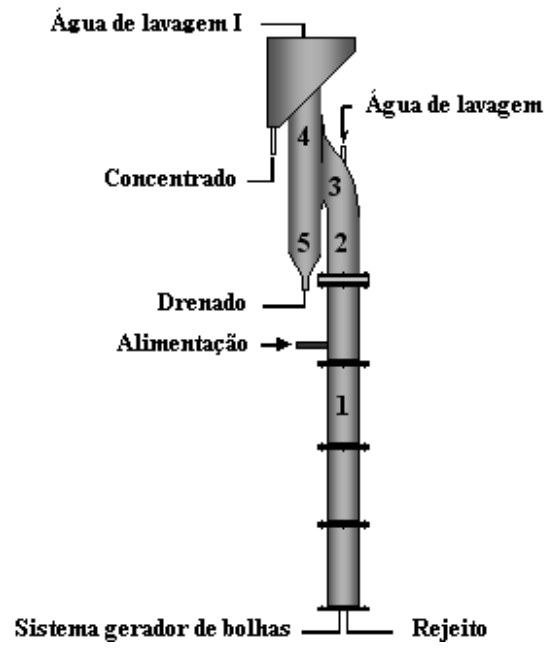

1. Zona de coleção: entre o borbulhador e o ponto de alimentação;

2. Zona de lavagem intermediária: entre a alimentação e o ponto de adição da segunda água de lavagem;

3. Zona de inflexão

4. Zona de limpeza: espuma

5. Zona de partículas drenadas da fase espuma

Figura 1. Coluna modificada de três produtos (C3P) do LTM-DEMIN-UFRGS.

\section{RESULTADOS E DISCUSSÃO}

Estudos de caracterização: A distribuição de arsênio foi homogênea (uniforme) na concentração, em toda faixa granulométrica analisada, como mostra a figura 2 A. A figura 2 B apresenta o difratograma da amostra de minério de fosfato. As principais espécies minerais identificadas foram hidroxiapatita, actinolita, hornblenda, tremolita, clorita-serpentina, e quartzo. Os principais elementos identificados por MEV foram $\mathrm{Ca}, \mathrm{P}, \mathrm{Si}, \mathrm{Al}, \mathrm{Cl}, \mathrm{Mg}$ e Fe, como apresentam as figuras 2 (C,D). Não foram identificadas espécies de arsênio via DRX ou MEV devido a seu baixo teor.
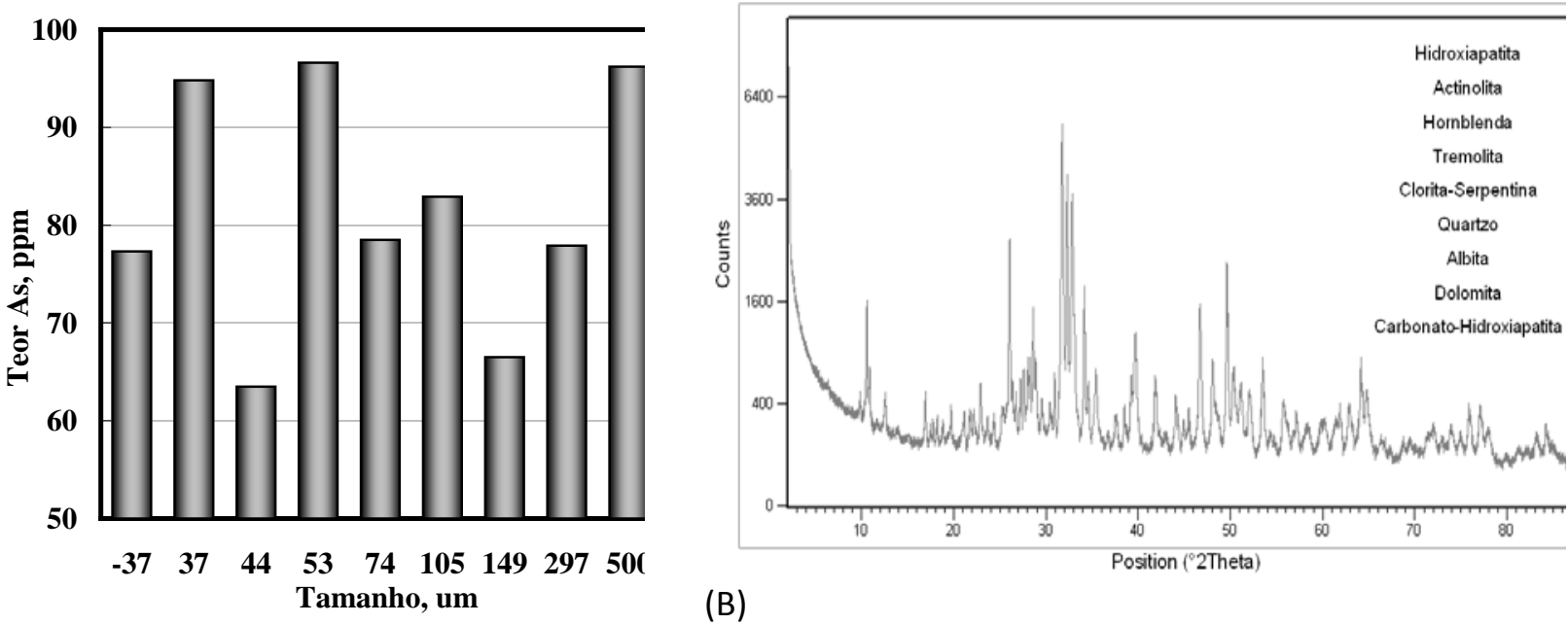

(B) 
(A)

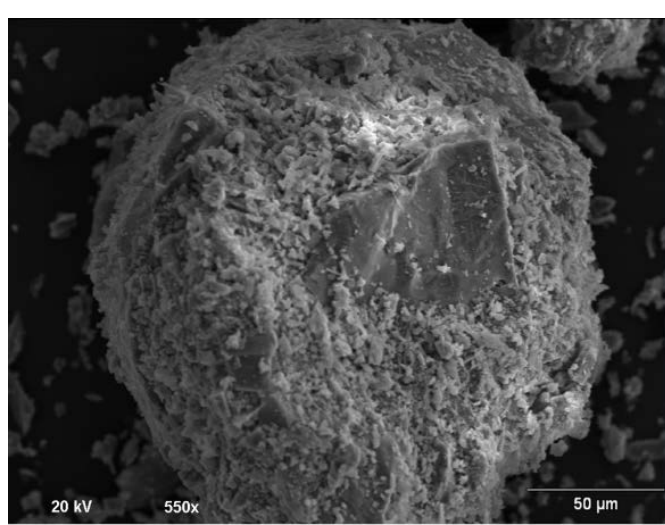

(C)

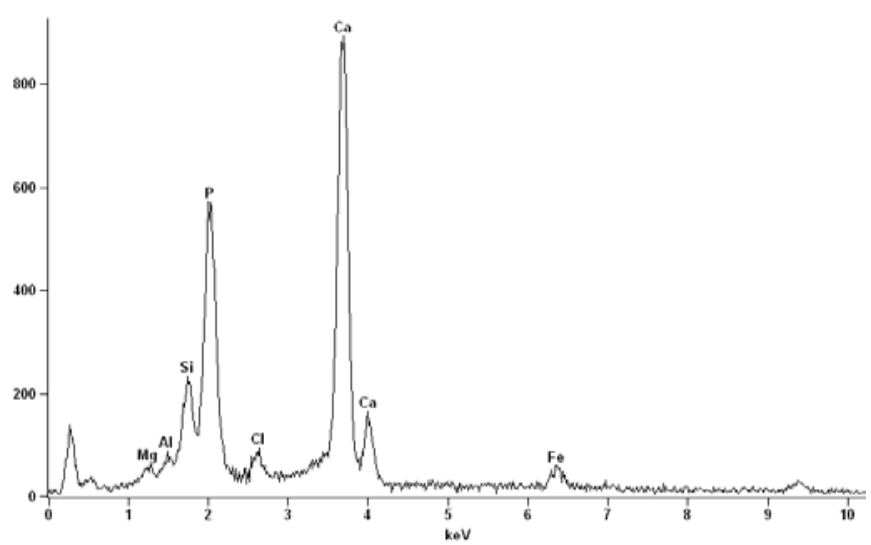

(D)

Figura 2. (A) Distribuição de teores de arsênio. (B) Difratograma da amostra de minério de fosfato e principais fases minerais identificadas. (C) Micrografia obtida por MEV. Magnificação: 550x. Voltagem: 20kV. Tempo de aquisição: 30 s. (D). Espectro por energia dispersiva da Figura 2 (C).

Os resultados de análises de $\mathrm{FRX}$ dos produtos de flotação permitiram estabelecer uma correlação direta entre $\mathrm{Ca}, \mathrm{P}$ e $\mathrm{As}$, e inversa entre $\mathrm{Fe}$ e $\mathrm{As}$, como identificado nas figuras 3 ( $\mathrm{A}, \mathrm{B}, \mathrm{C})$. Esta descoberta indica a associação do arsênio às espécies de apatita e não com as espécies dos minerais de ganga (principalmente as portadoras de ferro).

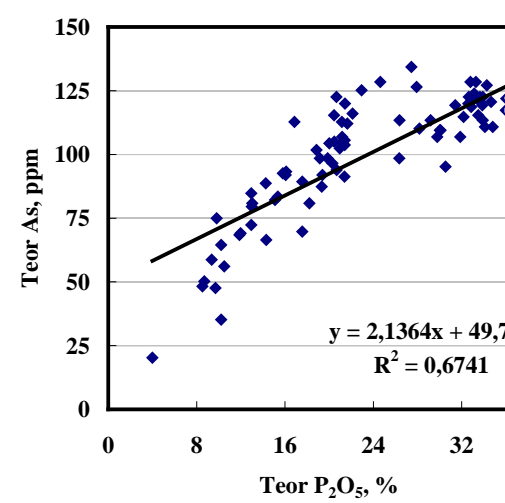

(A)

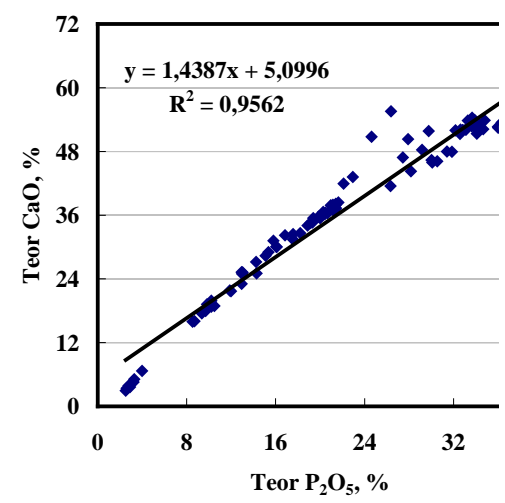

(B)

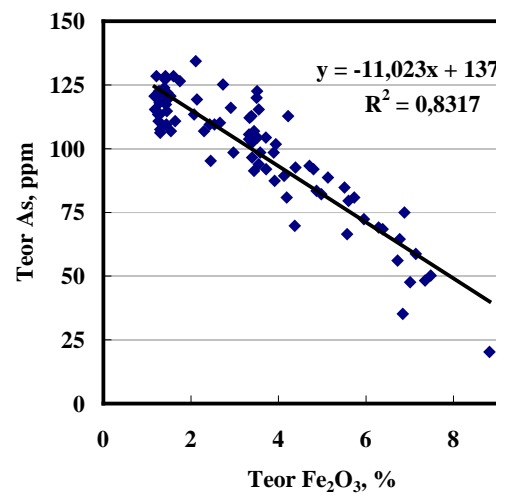

(C)

Figura 3. Correlação determinada entre os elementos $\mathrm{Ca}, \mathrm{P}$, Fe e As, com base nos resultados de análises químicas por FRX dos produtos da flotação.

Estudos de flotação: Ensaios em célula mecânica. As figuras 4 (A, B) apresentam o efeito da concentração de oleato de sódio e da adição de óleo diesel emulsificado sobre a recuperação e o teor de $\mathrm{P}_{2} \mathrm{O}_{5}$. A elevação da concentração de oleato de sódio resultou em um acréscimo na recuperação de $\mathrm{P}_{2} \mathrm{O}_{5}$, e o teor de $\mathrm{P}_{2} \mathrm{O}_{5}$ mantendo-se entre $38-39 \%$ o que comprova a alta seletividade desta rota, principalmente em função da adsorção química entre o grupo carboxílico do coletor e os íons cálcio superficiais do fosfato. Estes coletores foram selecionados após seguir inúmeras rotas tradicionais, que não apresentaram qualquer seletividade. 


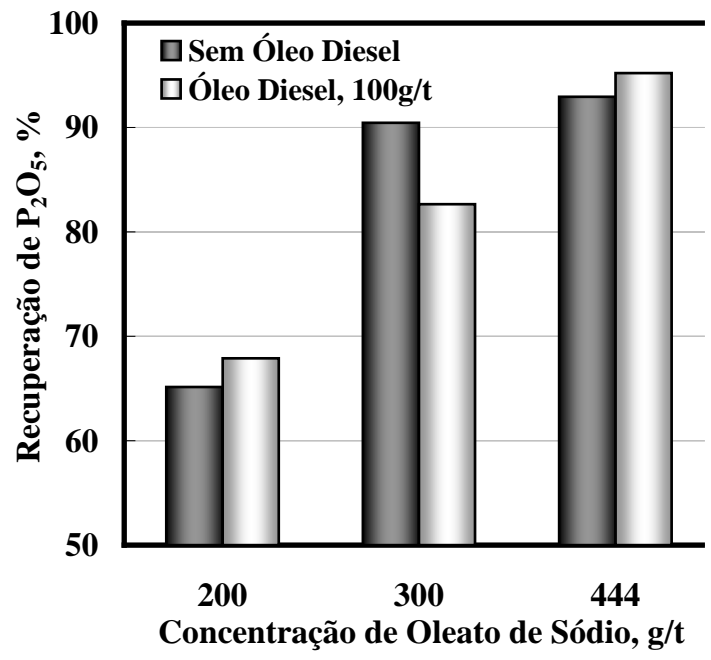

(A)

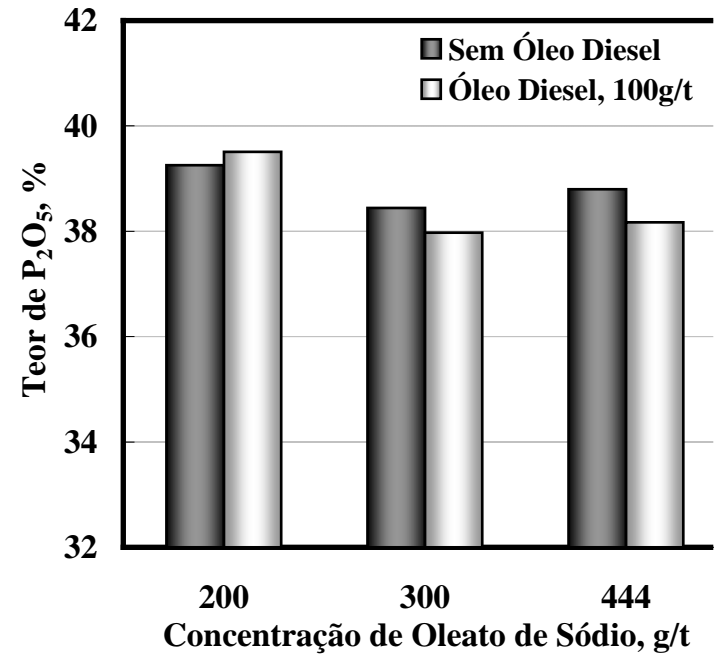

(B)

Figura 4. Efeito da concentração de coletor (oleato de sódio) e da adição de agente extensor sobre a recuperação e teor de $\mathrm{P}_{2} \mathrm{O}_{5}$.

A tabela II apresenta os teores de impurezas, razão $\mathrm{CaO} / \mathrm{P}_{2} \mathrm{O}_{5}$ e BPL (Bone Phosphate of Lime) dos produtos concentrados dos testes de flotação. O conteúdo de impurezas, com exceção do arsênio, se manteve baixo, com níveis aceitáveis à produção de fertilizantes fosfatados, comprovando a especificidade da rota escolhida de flotação.

Tabela II. Efeito da concentração de coletor (oleato de sódio) e da adição de agente extensor sobre os teores médios de impurezas, razão $\mathrm{CaO} / \mathrm{P}_{2} \mathrm{O}_{5}$ e BPL dos concentrados da flotação.

\begin{tabular}{c|c|r|r|r|r|r}
\hline $\begin{array}{c}\mathrm{Fe}_{2} \mathrm{O} \\
3, \%\end{array}$ & $\begin{array}{c}\mathrm{As}, \\
\mathrm{ppm}\end{array}$ & $\begin{array}{c}\mathrm{Mg} \\
\mathrm{O}, \%\end{array}$ & $\begin{array}{c}\mathrm{Al}_{2} \\
\mathrm{O}_{3}\end{array}$ & $\begin{array}{r}\mathrm{Si} \\
\mathrm{O}_{2}, \%\end{array}$ & $\begin{array}{r}\mathrm{CaO} / \\
\mathrm{P}_{2} \mathrm{O}_{5}\end{array}$ & $\begin{array}{r}\mathrm{E} \\
\mathrm{PL}\end{array}$ \\
\hline 0,7 & 109 & 0,2 & 0,3 & 1,9 & 84,6 & 1 \\
\hline
\end{tabular}

Ensaios em coluna. A tabela III mostra os resultados comparativos de teores dos produtos entre CCR e C3P. Os produtos concentrado e rejeito de ambas as células apresentaram valores de teores muito próximos. Porém, o produto concentrado da C3P apresentou sempre teores de $\mathrm{P}_{2} \mathrm{O}_{5}$ superior $(\sim 1,7 \%)$ ao da CCR, além de menores conteúdos de As. Já o drenado, obtido como terceiro produto da C3P mostrou características similares ao material que alimenta a flotação, sugerindo uma recirculação à alimentação, diminuindo as perdas para a corrente do rejeito.

Tabela III. Resultados comparativos entre produtos dos ensaios realizados em CCR e C3P.

\begin{tabular}{|c|c|c|c|c|c|}
\hline \multirow{2}{*}{ es $\begin{array}{r}\text { Teor } \\
\end{array}$} & \multicolumn{2}{|l|}{ CCR } & \multicolumn{3}{|l|}{ C3P } \\
\hline & $\begin{array}{l}\text { Concent } \\
\text { rado }\end{array}$ & $\begin{array}{l}\text { Re } \\
\text { jeito }\end{array}$ & $\begin{array}{l}\text { Concent } \\
\text { rado }\end{array}$ & $\begin{array}{l}\text { Dre } \\
\text { nado }\end{array}$ & $\begin{array}{l}\text { Re } \\
\text { jeito }\end{array}$ \\
\hline$\%{ }^{\mathrm{P}_{2} \mathrm{O}_{5}}$ & 38 & $4^{1,}$ & 40 & 16 & $0^{1,}$ \\
\hline$\%$ CaO, & 53 & $1^{5,}$ & 53 & 33 & $0^{4,}$ \\
\hline${ }_{3, \%} \mathrm{Fe}_{2} \mathrm{O}$ & 0,8 & $\begin{array}{ll}10 \\
, 1\end{array}$ & 0,7 & 5,5 & 9 \\
\hline
\end{tabular}




\begin{tabular}{|c|c|c|c|c|c|}
\hline $\begin{array}{c}\text { As, } \\
\mathrm{ppm}\end{array}$ & 185 & 27 & 124 & 115 & ${ } 0^{18}$ \\
\hline,$\%{ }^{\mathrm{MgO}}$ & 0,2 & $0^{3,}$ & 0,2 & 1,7 & $0^{3,}$ \\
\hline$\% \mathrm{SiO}_{2}$, & 1,8 & 14 & 1,8 & 8,0 & $0^{14}$ \\
\hline${ }_{3, \%} \mathrm{Al}_{2} \mathrm{O}$ & 0,3 & $4^{9}$ & 0,3 & 6,2 & $6^{12}$ \\
\hline
\end{tabular}

\section{CONCLUSÕES}

Foi desenvolvida uma técnica de FRX para a caracterização química do fosfato e foram estabelecidas as correlações determinadas entre $\mathrm{P}, \mathrm{Ca}$, Fe e As. Foi possível concluir que o As está associado aos minerais de apatita, sendo o $\mathrm{P}$ substituído pelo As em sua estrutura, dificultando a remoção por métodos físicos. Os melhores resultados de flotação em célula mecânica foram obtidos com a amostra "enriquecida" e classificada entre 37-149 $\mu \mathrm{m}$, oleato de sódio como coletor (444g/t) e óleo diesel $(100 \mathrm{~g} / \mathrm{t}$ ) como co-coletor "extender". Os teores (médios) dos concentrados foram $39 \%$ de $\mathrm{P}_{2} \mathrm{O}_{5}$, superiores ao teor mínimo estabelecido como meta, $109 \mathrm{ppm}$ de As e baixas concentrações de impurezas $\left(1,9 \% \mathrm{SiO}_{2}, 0,7 \% \mathrm{Fe}_{2} \mathrm{O}_{3}, 0,2 \% \mathrm{MgO}\right.$ e $\left.0,3 \% \mathrm{Al}_{2} \mathrm{O}_{3}\right)$, elevadas recuperações de $\mathrm{P}_{2} \mathrm{O}_{5}(>96 \%)$, taxas de $\mathrm{BPL}$ de $84,6 \%$ e razão $\mathrm{CaO} / \mathrm{P}_{2} \mathrm{O}_{5}$ de 1,3 , mostrando a elevada seletividade do processo de tratamento desenvolvido. Esses resultados foram validados nos estudos de flotação de coluna obtendo-se concentrados de alta qualidade, com elevados teores de $\mathrm{P}_{2} \mathrm{O}_{5}$ e baixo conteúdo de impurezas. A coluna modificada de três produtos-C3P gerou os concentrados de maior pureza do que os obtidos em coluna convencional reta, em função da retirada do produto drenado (mistos e partículas arrastadas) da fase espuma. Esses resultados comprovam o grande potencial desta coluna na obtenção de concentrados de alto teor, o que possibilita seu uso como unidade Rougher-Flash, de limpeza e no tratamento de rejeitos. Acredita-se que, em função dos concentrados de alto teor e reduzido conteúdo de impurezas, seria possível a produção de fertilizantes fosfatados, atingindo os objetivos do estudo.

\section{AGRADECIMENTOS}

Os autores agradecem à CAPES e ao CNPq pelo suporte financeiro aos bolsistas. À UFRGS, ao PPGE3M, e à Minera Formas, pelo apoio para a realização deste trabalho. Aos professores, técnicos e estudantes do LTM pelo companheirismo e apoio na parte experimental.

\section{REFERÊNCIAS BIBLIOGRÁFICAS}

1. Abouzeid, A. M. Physical and Thermal Treatment of Phosphate Ores - An Overview. International Journal of Mineral Processing, v. 85, pp. 59-84, 2008.

2. Barros, L. A. F. Concentração de Minérios Fosfáticos em Teoria e Prática do Tratamento de Minérios, Vol.4. Flotação O Estado da Arte no Brasil, pp. 83-121, 1 Ed., São Paulo, 2006.

3. Cabral, S., Rubio, J. Flotação coletiva de sulfetos de $\mathrm{Zn}$ e $\mathrm{Pb}$ em coluna C3P. III Mining Italian-Brazilian Congress, Canela, RS, Brasil, pp. 522-530, 1996. 
4. Loureiro, F. E. L., Monte, M. B. M., Nascimento, M. Agrominerais - Fosfato em Rochas \& Minerais Industriais - Usos e especificações, pp. 141-174, 2 Ed. Rio de Janeiro, CETEM, 2008.

5. Matiolo, E., Rubio, J., Centeno, C. Flotação primária de minérios de fosfato em coluna de três produtos (C3P). Em: Anais XXIII Encontro Nacional de Tratamento de Minérios e Metalurgia Extrativa, Gramado, Brasil, Vol. 2, pp. 301-308, 2009.

6. Rubio, J., López, D.A.R. Processo de flotação de finos de fluorita em coluna modificada. Proceedings of the III Meeting of the Southern Hemisphere on Mineral Technology, Flotação: Fundamentos, Prática e Meio Ambiente, Belo Horizonte, Brasil, pp. 369-388, 1992.

7. Rubio, J. Modified column flotation of mineral particles. Internationl Journal of Mineral Processing. 48, pp. 183-196, 1996.

8. Santander, M. E., Beas, E., Rubio, J. Flotación em coluna modificada de sulfuros de cobre. Anais do IV Southern Hemisphere Meeting on Mineral Technology, Concepción-Chile, (Eds) S. Castro e J. Alvarez, Vol. 4, pp. 165-178, 1994.

9. Sis, H., Chander, S. Reagents Used in the Flotation of Phosphate Ores: A Critical Review. Minerals Engineering, v.16, p. 577-585, 2003.

10. Snow, R. E. Flotation of Phosphate ores containing Dolomite. United States Patent, № 4.364.824, 1982.

11. Valderrama, L., Rubio, J. Unconventional column flotation of low-grade gold fine particles from tailings. International Journal of Mineral Processing. 86, 1-4, pp 75-84, 2008.

12. Zhang, P., Yu, Y., Bogan, M. Challenging the "Crago" Double Float Process II. AmineFatty Acid

13. Flotation of Siliceous Phosphates. Minerals Engineering, v.10, p. 983-994, 1997. 